\title{
The Determination of Inorganic Sulphate in Serum and Synovial Fluid by High Performance Ion Chromatography
}

\author{
Ruediger Kock, Heike Schneider, Bert Delvoux and Helmut Greiling
}

Institut für Klinische Chemie und Pathobiochemie, Medizinische Fakultät der RWTH Aachen, Universitätsklinikum der RWTH Aachen, Aachen, Germany

Summary: A method for the determination of inorganic sulphate based on high performance ion chromatography is presented. The separation was performed on an anion-exchange column with a $1.8 \mathrm{mmol} / \mathrm{l}$ sodium carbonate/ $1.7 \mathrm{mmol} / \mathrm{l}$ sodium hydrogen carbonate-buffer, $\mathrm{pH} 10.35$. Conductivity of the eluate was monitored after suppression of the background conductivity caused by the eluent-buffer.

Serum and synovial fluid samples were prepared by ultrafiltration through membranes with a molecular mass cutoff of $M_{\mathrm{r}} 10000$. The viscosity of the synovial fluids was reduced by treatment with hyaluronate lyase before ultrafiltration.

The method showed a linear response for sulphate concentrations between 0.5 and $1000 \mu \mathrm{mol} / \mathrm{l}$. The limit of detection was $1 \mu \mathrm{mol} / 1$ for aqueous standards. For serum the coefficient of variation within-run was $2.3 \%-2.4 \%$, the coefficient of variation between days $2.9 \%-3.1 \%$. For synovial fluids the coefficient of variation within-run was $3.1 \%-3.4 \%$, the coefficient of variation between days $4.6 \%-5.7 \%$. Standard recovery experiments performed by spiking pools of human sera containing low sulphate concentrations with sulphate concentrations between $5 \mu \mathrm{mol} / 1$ and $40 \mu \mathrm{mol} / 1$ showed recoveries between $98.9 \%$ and $100.6 \%$. The corresponding experiments with pools of synovial fluids showed recoveries of $98.3 \%$ to $100.9 \%$.

As determined from 127 serum samples the reference range for sulphate was $262 \mu \mathrm{mol} / 1-420 \mu \mathrm{mol} / \mathrm{l}$, with a mean value of $314 \mu \mathrm{mol} / 1$. No dependence on age or sex was observed.

The sulphate concentration in 36 synovial fluids from knees affected by inflammatory processes showed a mean value of $424 \mu \mathrm{mol} / 1$ and a standard deviation of $70 \mu \mathrm{mol} / 1$. In 41 synovial fluids from knees affected by chronic degenerative joint disease, the sulphate concentrations were statistically significantly lower, with a mean of $374 \mu \mathrm{mol} / 1$ and a standard deviation of $58 \mu \mathrm{mol} / 1$. The concentrations of sulphate in the synovial fluids were statistically significantly higher than those in the serum samples used for determination of the reference range.

Following the oral application of a subtoxic single dose of acetaminophen $(32.5 \mathrm{mg} / \mathrm{kg}$ body weight $-62.5 \mathrm{mg} / \mathrm{kg}$ body weight) to 4 healthy volunteers, there was a significant decrease in the concentration of sulphate in serum with a minimum at $4-5 \mathrm{~h}$ after application of the drug. The cumulative concentration decrease of sulphate in serum and the kinetic constant of the sulphate depletion were not correlated with the applied acetaminophen dose normalized for body weight.

\section{Introduction}

The main biological function of inorganic sulphate is to serve as a conjugation partner by forming sulphate esters with hydroxyl groups of endogeneous or exogeneous metabolites. Adenosine triphosphate reacts with inorganic sulphate to form adenosine-5'-phosphosulphate and pyrophosphate; in a second reaction a phosphate group is transferred from a second adenosine triphosphate to adenosine-5'-phosphosulphate to give the "active sulphate", 3'-phosphoadenosine-5'-phosphosulphate, as well as adenosine diphosphate. The reaction is thermodynamically partially driven by the enzymatic

hydrolysis of the intermediate metabolite, pyrophosphate, to orthophosphate.

The conjugation process depends on a sulphotransferase, which catalyses the transfer of a sulphate group to the alcoholic or phenolic hydroxyl groups of the metabolite from 3'-phosphoadenosine-5'-phosphate. Bile acids, steroids and catecholamines (1) are subject to this type of conjugation, but sulphatation is also a vital step in the biosynthesis of proteoglycans and metabolites like sulphocerebrosides. Sulphoconjugation also occurs in the detoxification of serveral drugs, for example salicyl- 
amide, $\alpha$-methyldopa and acetaminophen, which contain alcoholic or phenolic hydroxyl groups.

In synovial fluid the concentration of inorganic anions is regulated by Donnan equilibrium, and the concentrations of anions like chloride and phosphate have been found to be higher than in serum. More recent studies (2-4) have shown that drugs used in the therapy of primary chronic polyarthritis decrease the sulphate content of the glycosaminoglycans synthesized in cartilage.

In the present study a high performance ion chromatography (HPIC) method for the determination of sulphate is reported. This was applied to the analysis of serum and synovial fluid. An ultrafiltration procedure suitable for the biological materials studied was used for the required deproteinization (5-6), and the effects of this sample preparation on the analytical results were minimized. A reference range for the concentration of sulphate in serum was established by analysing sera from 127 individuals. The concentrations of sulphate in synovial fluids from patients with chronic degenerative joint disease $(n=41)$ were compared with those in synovial fluids from patients with inflammatory joint disease $(n=36)$. Finally, the method was applied to kinetic studies on the metabolism of subtoxic dosis of acetaminophen in 4 healthy volunteers.

\section{Materials and Methods}

\section{Chemicals}

Potassium sulphate, $950 \mathrm{~g} / \mathrm{kg}$ sulphuric acid, sodium carbonate, sodium hydrogen carbonate and $250 \mathrm{~g} / \mathrm{kg}$ hydrochloric acid in at least p. a. quality were from Merck (Darmstadt, Germany). Isotonic sodium chloride solution (154 mmol/1) was from Clinitec Salvia (Homburg/Saar, Germany). Hyaluronate lyase isolated from Streptomyces hyalurolyticus was obtained from Behringwerke AG (Liederbach, Taunus). The deionized water was prepared with a MilliQ-apparatus (Millipore $\mathrm{GmbH}$, Eschborn, Germany).

The acetaminophen used for the kinetic studies was orally administered to 4 healthy volunteers as ben-u-ron ${ }^{\circledR} 500 \mathrm{mg}$ tablets in one dose (33-62.5 $\mathrm{mg} / \mathrm{kg}$ weight).

For determination of acetaminophen in serum a fluorescence polarisation immunoassay was used. The appropriate reagent kits and controls for the TDX-FLX ${ }^{\circledR}$-system were obtained from Abbott GmbH (Wiesbaden-Delkenheim, Germany).

All blood specimens were collected in Sarstedt serum monovettes containing separation gel. The reference range was determined from serum samples drawn after $12 \mathrm{~h}$ fasting, when the basic clinical chemistry $\mathrm{Na}, \mathrm{K}, \mathrm{Cl}, \mathrm{Ca}$, inorganic phosphate, total protein, total cholesterol, triacylglycerols, glucose, uric acid, urea, creatinine, total bilirubin, aspartate aminotransferase, alanine aminotransferase, $\gamma$-glutamyltransferase, alkaline phosphatase and total creatine kinase) did not show any pathological abnormalities.

The synovial fluids used in this study were obtained from diagnostic or therapeutic punctions of the knee joint of patients with inflammatory and chronic joint affections.

Instruments, settings and procedures

\section{Ultrafiltration}

The ultrafiltration was performed on an Amicon MPS-1 system with YMT 30 100PK 14 mm membranes (Amicon, Witten, Germany).

\section{High performance ion chromatography}

The chromatographic analysis was performed on a HPLC-system consisting of an ion chromatograph DX-100 (DIONEX GmbH, Idstein, Germany), containing an isocratic HPLC-pump and a conductivity detector, connected to an autosampler WISP 710B (Waters GmbH, Eschborn, Germany) and a Maxima 820 chromatography manager with a two channel system-interface-module (Waters GmbH, Eschborn, Germany) for system control, data acquisition and peak integration. The complete fluidic of the autosampler was passivated by $30 \%$ nitric acid before use.

For separation, an Ion-Pac AS4A $(250 \mathrm{~mm} \times 4 \mathrm{~mm}$, DIONEX GmbH, Idstein, Germany), combined with a AG4A (40 mm $\times 4 \mathrm{~mm}$, DIONEX GmbH, Idstein, Germany) was used. The eluent contained $1.7 \mathrm{mmol} / 1 \mathrm{Na}_{2} \mathrm{CO}_{3}$ and $1.8 \mathrm{mmol} / 1 \mathrm{NaHCO}_{3}$ in deionized water, $\mathrm{pH} 10.35$; the flow rate was set to $2.0 \mathrm{ml} / \mathrm{min}$; the pressure in the chromatographic system did not exceed 140 bar. The retention times in this system were $1.2 \mathrm{~min}$ for fluoride, 2.3 min for chloride, 5.4 for phosphate and $6.2 \mathrm{~min}$ for sulphate.

The eluent of the column was passed through an anionic micromembrane suppressor AMMS-II (DIONEX GmgH, Idstein, Germany) integrated in the DIONEX DX-100 instrument for the elimination of the background conductivity caused by the carbonate buffer system. This ion exchanger was regenerated continuously by $50 \mathrm{mmol} / \mathrm{l}$ sulphuric acid. The conductivity was measured at a sensitivity range of $10 \mu \mathrm{S}$ full scale. The system was calibrated for sulphate concentrations between $10 \mu \mathrm{mol} / 1$ and $100 \mu \mathrm{mol} / 1$ sulphate with 4 standard solutions $(10-25-50-100 \mu \mathrm{mol} / \mathrm{l})$ prepared from a stock standard containing $1 \mathrm{mmol} / \mathrm{l}$ sodium sulphate by volumetric dilution.

\section{Analysis of the serum samples}

Serum $(150 \mu l)$ was diluted with deionized water to give a final volume of $1500 \mu \mathrm{l}$. Of this diluted serum $500 \mu \mathrm{l}$ were filtered through the MPS-1-ultrafiltration device by centrifugation at $2000 \mathrm{~g}$ and $4{ }^{\circ} \mathrm{C}$ for $25 \mathrm{~min}$; the resulting $400 \mu \mathrm{l}$ ultrafiltrate were discarded. Then $900 \mu \mathrm{l}$ diluted serum were filtered through the same membrane under the same conditions. Of this ultrafiltrate $50 \mu \mathrm{l}$ were injected by the autosampler for analysis by ion chromatography.

\section{Analysis of the synovial fluid samples}

Hyaluronate lyase $(150 \mathrm{mg}, 300-400$ Units $/ \mathrm{mg}$ ) was dissolved in $100 \mathrm{ml}$ isotonic sodium chloride $(154 \mathrm{mmol} / \mathrm{l})$. Ten (10) $\mu \mathrm{l}$ of this solution were added to $300 \mu \mathrm{l}$ synovial fluid and the mixture incubated for $30 \mathrm{~min}$ at $37^{\circ} \mathrm{C}$. After degradation of the hyaluronate the viscosity of the synovial fluid was comparable to that of serum. Hundred and fifty $(150) \mu l$ of this mixture were then treated as described for serum samples.

\section{Statistical calculations}

All statistical calculations were done with the aid of the software package Jandel Sigmastat Version 1 (Jandel Scientific GmbH, Schimmelbuschstraße 25, D-40699 Erkrath, Germany). The Kolmogorov-Smirnov test with Lilliefors' correction was used to test data for normality of the estimated underlying population. The two sample t-test was used for the parametric comparison of two samples, which were drawn from normally distributed populations with the same variances.

\section{Results}

\section{Chromatography}

Ultrafiltration proved to be a suitable method of sample preparation for the determination of sulphate in serum and in synovial fluid. Figure 1a shows the chromatogram of a sulphate standard, figure $1 \mathrm{~b}$ that of a serum 
ultrafiltrate, figure 1c that of a synovial fluid ultrafiltrate. Chloride and phosphate were well separated from sulphate, and no other anion interfering with sulphate was observed.

The signal of the conductivity detector was linear for injected amounts of $500 \mathrm{pmol}$ to $50 \mathrm{nmol}$, equivalent to the concentration range $10 \mu \mathrm{mol} / 1-1000 \mu \mathrm{mol} / 1$ (data shown in figure 2).

\section{Optimization of the ultrafiltration}

The ultrafiltration membranes showed a significant content of sulphate and a capacity for the unspecific adsorption of sulphate. The recovery of an aqueous solution containing $0.625 \mu \mathrm{mol} / 1$ sulphate was $170-200 \%$, that of a solution containing $80 \mu \mathrm{mol} / 1$ sulphate was $80-90 \%$, regardless of whether the membranes were previously conditioned with deionized water or not. This effect could be minimized by a two-step ultrafiltration procedure, discarding the ultrafiltrate of the first $500 \mu \mathrm{l}$ aliquot of the diluted serum/synovial fluid, and using the second ultrafiltrate. Using this sample preparation we studied the effect of serum protein on the fraction of ultrafiltratable sulphate by standard recovery experi-

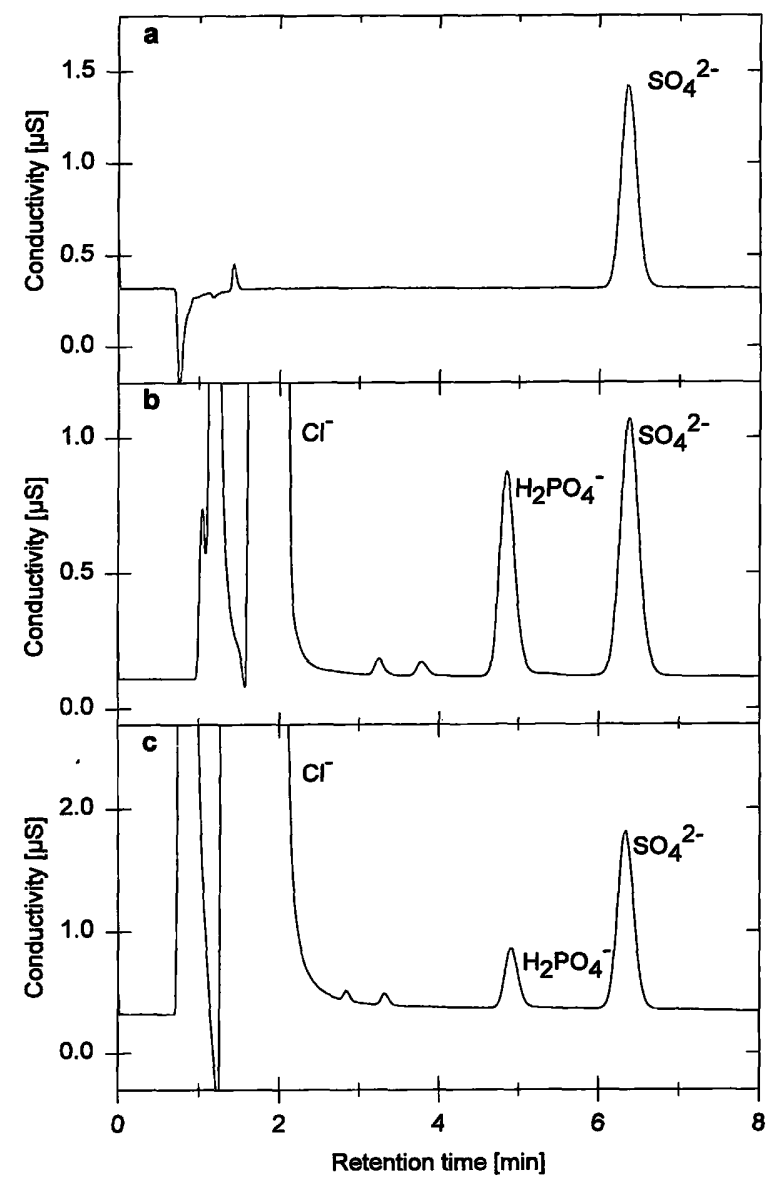

Fig. 1a-c Chromatogram of

(a) a sulphate standard containing $250 \mu \mathrm{mol} / 1$ sulphate,

(b) a serum sample containing $232 \mu \mathrm{mol} / 1$ sulphate and

(c) a synovial fluid sample containing $307 \mu \mathrm{mol} / 1$ sulphate.

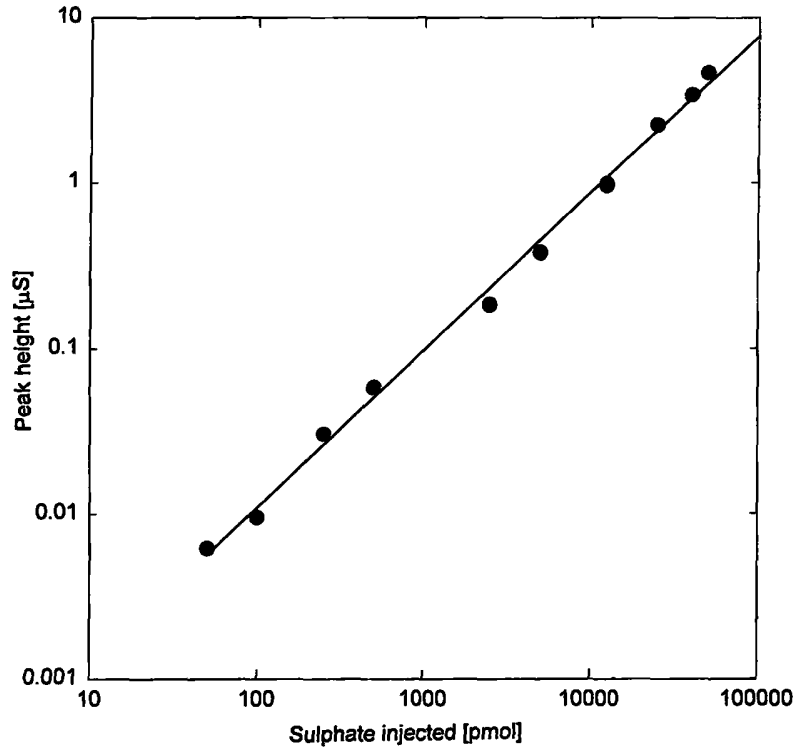

Fig. 2 Linearity of the peak height in dependence on the amount of sulphate injected into the ion-chromatograph.

ments. A serum pool (sulphate concentration: 350 $\mu \mathrm{mol} / \mathrm{l})$ was prepared, then $150 \mu \mathrm{l}$ serum pool, $150 \mu \mathrm{l}$ of a sulphate standard and $1200 \mu \mathrm{l}$ deionized water were mixed, and this dilution was ultrafiltered. Synovial fluids were pretreated with hyaluronate lyase, pooled and then processed like the pooled sera. Table 1 summarizes the results of these experiments, which showed a $100 \%$ recovery for the range $5 \mu \mathrm{mol} / 1$ to $40 \mu \mathrm{mol} / 1$ sulphate added to both the $1: 10$ dilutions of the pooled sera and the $1: 10$ dilutions of the pooled synovial fluids.

\section{Imprecision}

The within-run imprecision (tab. 2a) was below $1.5 \%$ for standards, below $2.5 \%$ for the pooled sera and below $3.5 \%$ for the pooled synovial fluids. The between-run imprecision (tab. $2 \mathrm{~b}$ ) was about $3 \%$ for the pooled sera and below $6 \%$ for the pooled synovial fluids. The theoretical limit of detection was $1.05 \mu \mathrm{mol} / 1$, determined by the method described by Long \& Winefolder (7), considering the standard deviations of the quantities describing the calibration line, as well as the mean and

Tab. 1 Recovery of sulphate standard added to a $1: 10$ diluted pool of human sera (sulphate concentration $375 \mu \mathrm{mol} / \mathrm{l}$ ) and to a $1: 10$ diluted pool of synovial fluids (sulphate concentration 290 $\mu \mathrm{mol} / \mathrm{h})$, ultrafiltered after standard addition $(\mathrm{n}=10$ determinations)

\begin{tabular}{lrc}
$\begin{array}{l}\text { Sulphate concentration } \\
{[\mu \mathrm{mol} / 1] \text { added to }} \\
1: 10 \text { dilution of pooled } \\
\text { sera/synovial fluids }\end{array}$ & $\begin{array}{l}\text { Recovery [\%] } \\
\text { in serum }\end{array}$ & $\begin{array}{l}\text { Recovery [\%] } \\
\text { in synovial fluid }\end{array}$ \\
\hline 5 & & \\
15 & $99.4 \pm 4.2$ & $100.9 \pm 0.6$ \\
25 & $100.6 \pm 3.9$ & $98.5 \pm 2.3$ \\
40 & $98.9 \pm 2.0$ & $98.9 \pm 1.4$ \\
\hline
\end{tabular}


Tab. 2a Within-run imprecision for the determination of sulphate, calculated for four standards, two pooled human sera and two pooled synovial fluids, calculated from $n=10$ runs of the
$1: 10$ dilutions of the standards or the ultrafiltrates of $1: 10$ dilutions of the sera and synovial fluids.

\begin{tabular}{|c|c|c|c|c|c|c|c|c|}
\hline & \multicolumn{8}{|c|}{ Sulphate $[\mu \mathrm{mol} / 1]$} \\
\hline & $\begin{array}{l}\text { Standard } \\
1\end{array}$ & $\begin{array}{l}\text { Standard } \\
2\end{array}$ & $\begin{array}{l}\text { Standard } \\
3\end{array}$ & $\begin{array}{l}\text { Standard } \\
4\end{array}$ & $\begin{array}{l}\text { Pooled } \\
\text { serum } 1\end{array}$ & $\begin{array}{l}\text { Pooled } \\
\text { serum } 2\end{array}$ & $\begin{array}{l}\text { Pooled } \\
\text { synovial } \\
\text { fluid } 1\end{array}$ & $\begin{array}{l}\text { Pooled } \\
\text { synovial } \\
\text { fluid } 2\end{array}$ \\
\hline Target & 50 & 100 & 200 & 400 & - & - & - & - \\
\hline Mean & 49.2 & 101.5 & 202.3 & 397.5 & 289.2 & 376.4 & 311.3 & 406.2 \\
\hline $\mathrm{SD}$ & 0.8 & 1.4 & 2.8 & 4.8 & 6.9 & 8.7 & 10.6 & 12.6 \\
\hline $\mathrm{CV}$ in $\%$ & 1.6 & 1.4 & 1.4 & 1.2 & 2.4 & 2.3 & 3.4 & 3.1 \\
\hline
\end{tabular}

Target $=$ the concentration assigned to the standards, which were also used for calibration of the method.

Tab. 2b Between-run imprecision for the determination of sulphate, calculated for two pooled human sera and two pooled synovial fluids, calculated from $n=10$ runs of the ultrafiltrates of $1: 10$ dilutions of the sera and synovial fluids.

\begin{tabular}{lcccc}
\hline \multicolumn{5}{c}{ Sulphate $[\mu \mathrm{mol} / 1]$} \\
\cline { 2 - 5 } & $\begin{array}{l}\text { Pooled } \\
\text { serum }\end{array}$ & $\begin{array}{l}\text { Pooled } \\
\text { serum }\end{array}$ & $\begin{array}{l}\text { Pooled } \\
\text { synovial } \\
\text { fluid 1 }\end{array}$ & $\begin{array}{l}\text { Pooled } \\
\text { synovial } \\
\text { fluid 2 }\end{array}$ \\
\hline Mean & 285.3 & 384.3 & 316.4 & 414.3 \\
SD & 8.8 & 11.1 & 18.0 & 19.1 \\
CV in \% & 3.1 & 2.9 & 5.7 & 4.6 \\
\hline
\end{tabular}

$\mathrm{SD}=$ Standard deviation

$\mathrm{CV}=$ Coefficient of variation in \%

the standard deviation of the peak-to-peak noise of the baseline signal.

\section{Reference range in serum}

The reference range for sulphate in serum was determined for serum samples from 69 male and 58 female subjects. The observed reference range showed no dependence on sex and age. For all 127 individuals the mean sulphate concentration in serum was $314 \mu \mathrm{mol} / \mathrm{l}$ with a standard-deviation of $36 \mu \mathrm{mol} / 1$, ranging from $262 \mu \mathrm{mol} / 1$ to $420 \mu \mathrm{mol} / \mathrm{l}$. The data did not match the pattern expected for data drawn from a normal distributed population (Komolgorov-Smirnov-test, K-S distance $=0.1151, \mathrm{P}=0.0007$ ).

\section{Sulphate concentration in pathological synovial fluids}

Figure 3 shows the distribution of the concentrations found for sulphate in pathological synovial fluids. For 36 synovial fluids from knees affected by inflammatory processes we obtained a range (mean \pm standard deviation) of $424 \mu \mathrm{mol} / 1 \pm 70.1 \mu \mathrm{mol} / 1$. For 41 synovial fluid from knees affected by chronic degenerative joint disease the range was (mean \pm standard deviation) $374 \mu \mathrm{mol} / 1 \pm 69.9 \mu \mathrm{mol} / 1$. The values for both
SD $=$ Standard deviation

$\mathrm{CV}=$ Coefficient of variation in \%

groups were as expected for data drawn from a normally distributed population and showed an equal variance. Comparison of the two groups by a t-test revealed a difference for the mean values greater than would be expected by chance $(t=3.09$ with 75 degrees of freedom, $\mathrm{P}=0.0028$ ).

\section{Kinetics of sulphate in serum following the administration of acetaminophen}

Figure 4 and table 3 summarize the data for the kinetic studies of the concentrations of sulphate and acetaminophen in serum following oral administration of a single

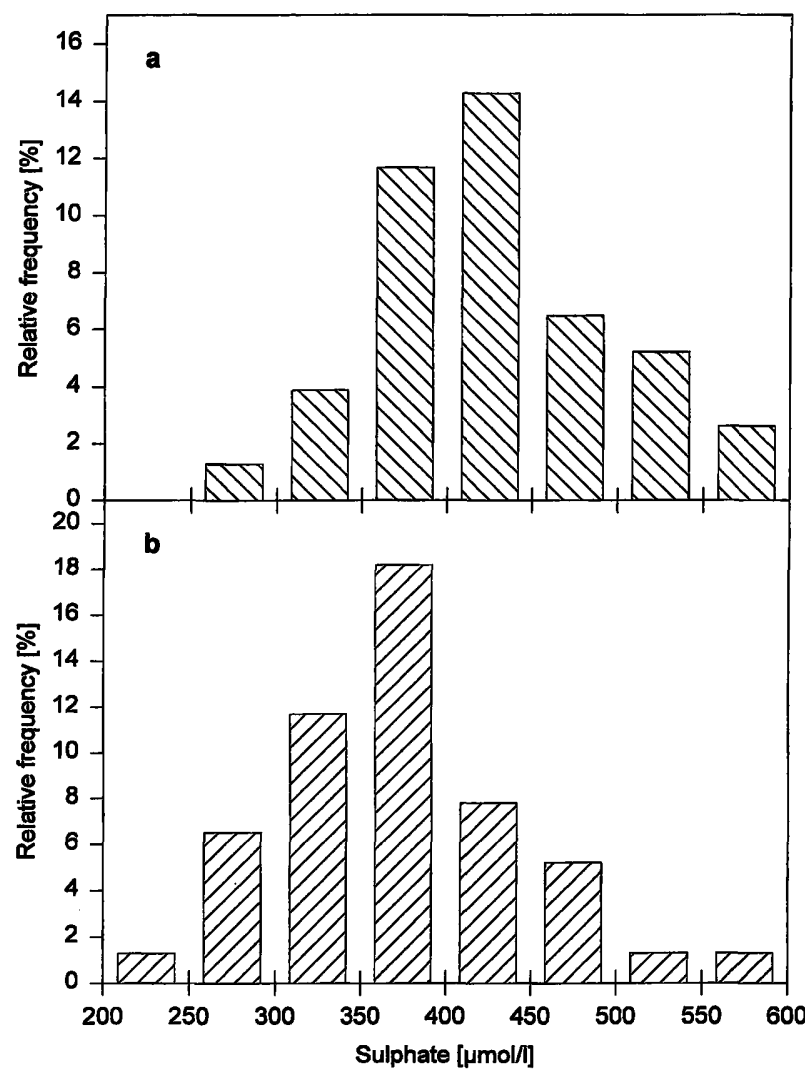

Fig. 3a-b Distribution of the sulphate concentrations measured in synovial fluid of (a) inflammatory joint diseases and (b) chronic degenerative joint diseases. 


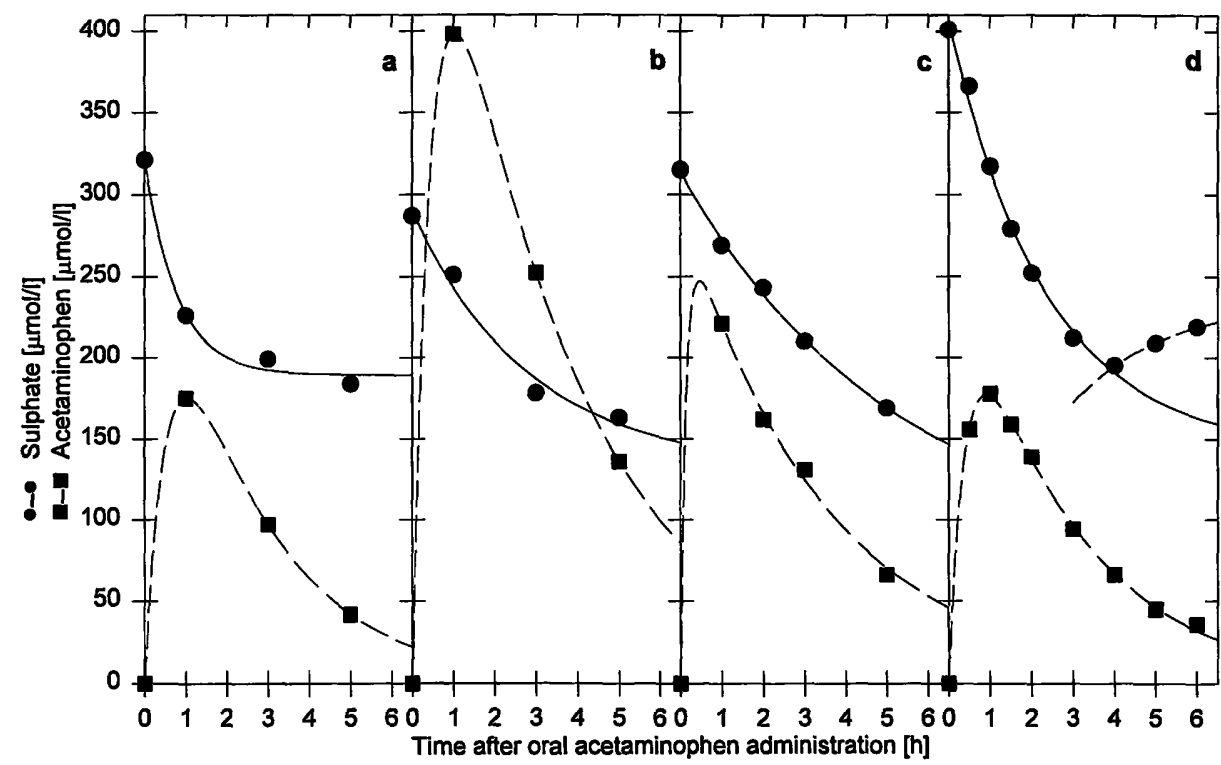

Fig. 4a-d Time-course of the decrease of sulphate and acetaminophen after administration of (a) acetaminophen $30 \mathrm{mg} / \mathrm{kg}$ body weight, (b) acetaminophen $62.5 \mathrm{mg} / \mathrm{kg}$ body weight, (d) acetaminophen $33 \mathrm{mg} / \mathrm{kg}$ body weight. (c) acetaminophen $50 \mathrm{mg} / \mathrm{kg}$ body weight,

- = acetaminophen concentration

dose of acetaminophen (33-62.5 $\mathrm{mg} / \mathrm{kg}$ body weight) to 4 healthy, previously fasting (for at least 12 hours) volunteers.

The resorption and metabolism of acetaminophen could be described as a first order kinetic process with a resorption constant larger than the elimination constant. The peak concentration of acetaminophen reached in serum, calculated from the Bateman equation (8) used for fitting the data, was correlated with the applied dose normalized for body weight. The decay constant $\mathrm{k}_{3}$ was $0.35 \pm 0.06 \mathrm{~h}^{-1}$ (mean \pm standard deviation). The metabolism of acetaminophen showed a decay constant of $0.35 \pm 0.06 \mathrm{~h}^{-1}$ (mean \pm standard deviation) for the four volunteers. In all cases, the decay kinetics of the sulphate in serum were also first order, but the variation of the decay constant $\mathrm{k}$ was large. Neither the kinetic constant nor the cumulative loss of sulphate in serum ( $41 \%$ to $74 \%$ of the initial sulphate concentration) due to the administration of acetaminophen were correlated with the applied dose of acetaminophen.

\section{Discussion}

The objective of this study was the determination of inorganic sulphate in serum and synovial fluid. Colorimetric methods using benzidine (9), barium chloranilate (10) or rhodizonate (11) as well as turbidimetric methods based on the detection of barium sulphate (12) have been described for the determination of inorganic sulphate in biological materials. All these methods have limited sensitivity and precision due to the required sample preparation procedures and the analytical principle; the results are also strongly influenced by the matrix of the sample analysed. Several slightly different methods for the determination of sulphate in serum by high-performance-ion-chromatography with conductivity detection have also been described $(5,13-16)$. The advantage of these methods is that deproteinization is the only sample pretreatment required. Furthermore, the quantification does not depend on the use of an internal standard. In the present study ultrafiltration was choosen for deproteinization, since it is more effective than precipi-

Tab. 3 Kinetic studies on sulphate consumption due to acetaminophen administration.

The kinetic of sulphate consumption was approximated as $c(t)=c_{\infty}+\left(c_{0}-c_{\infty}\right) \cdot e^{-k \cdot t}$.

The kinetic of acetaminophen was approximated as $\quad c(t)=k_{1} \cdot k_{2} \cdot\left(e^{-k_{2} \cdot t}-\left(e^{-k \cdot t}\right) /\left(k_{3}-k_{2}\right)\right.$.

\begin{tabular}{|c|c|c|c|c|c|c|c|c|}
\hline \multirow{3}{*}{$\begin{array}{l}\text { Volunteer } \\
\text { (sex) }\end{array}$} & \multirow{3}{*}{$\begin{array}{l}\text { Acetaminophen } \\
\text { administered } \\
\text { (mg/kg } \\
\text { body weight) }\end{array}$} & \multicolumn{4}{|c|}{ Sulphate kinetics } & \multicolumn{3}{|c|}{ Acetaminophen kinetics } \\
\hline & & \multirow{2}{*}{$\begin{array}{l}c_{0} \\
(\mu \mathrm{mol} / \mathrm{l})\end{array}$} & \multicolumn{2}{|l|}{$\mathbf{c}_{\infty}$} & \multirow{2}{*}{$\begin{array}{l}\text { Decay } \\
\text { constant k } \\
\left(\mathrm{h}^{-1}\right)\end{array}$} & \multirow{2}{*}{$\begin{array}{l}c_{\max } \\
(\mu \mathrm{mol} / \mathrm{l})\end{array}$} & \multirow{2}{*}{$\begin{array}{l}\text { Time at } \\
c_{\max } \\
\text { (h) }\end{array}$} & \multirow{2}{*}{$\begin{array}{l}\text { Decay } \\
\text { constant } k_{3} \\
\left(h^{-1}\right)\end{array}$} \\
\hline & & & $(\mu \mathrm{mol} / \mathrm{l})$ & $\left(\%\right.$ of $\left.c_{0}\right)$ & & & & \\
\hline $1 \hat{\sigma}$ & 30 & 321 & 189 & 59 & 1.23 & 175 & 1.03 & 0.43 \\
\hline $2 \sigma$ & 62.5 & 287 & 129 & 45 & 0.36 & 398 & 1.04 & 0.31 \\
\hline $3 \%$ & 50 & 315 & 82 & 26 & 0.19 & 323 & 0.16 & 0.29 \\
\hline $4 \stackrel{+}{9}$ & 33 & 401 & 136 & 34 & 0.43 & 178 & 0.91 & 0.37 \\
\hline
\end{tabular}


tation (16). No interference by a precipitation agent can occur, and sample preparation is much more reproducible and allows better standardization. The only drawback is the unspecific binding of sulphate to the ultrafiltration membranes. Methods for elimination of sulphate contamination of the ultrafiltration membranes have been described previously (5-6), but the issue of unspecific binding of the analyte from the samples to the membranes, leading to a reduced recovery as well as precision, was not addressed. The method described here involves a sequence of two ultrafiltrations of diluted aliquots of a sample. The function of the first step was to equilibrate the membranes with the sulphate of the individual samples; the ultrafiltrate obtained was discarded. Analysis of the ultrafiltrate of the second aliquot showed an imprecision lower than $2 \%$. The inaccuracy, assessed by standard recovery experiments, was also within these limits.

The reference range for sulphate in serum was studied in samples from blood-donors and apparently healthy volunteers and did not show any dependence on age and sex. The mean concentration in serum was $314 \mu \mathrm{mol} / \mathrm{l}$, and a broad, non-normal distribution from $242 \mu \mathrm{mol} / 1$ to $385 \mu \mathrm{mol} / 1$ was observed. This non-normal distribution may be due to inter-individual as well as intra-individual fluctuations of the sulphate concentration in serum arising from the present pool and recent intake of sulphate-generating aminoacids as well as the renal sulphate elimination. Since all samples were drawn in the morning from individuals who had fasted for at least 12 hours, effects due to recent nutritive ingestion of sulphate precursors and due to a circadian rhythm described previously (17) should have been prevented.

Furthermore we studied the sulphate concentration in 36 synovial fluids from knees affected by inflammatory processes and 41 synovial fluids from knees affected by chronic degenerative joint disease.

Non-pathological synovial fluids from patients without any joint disease were not available for ethical reasons, so the study was limited to the comparison of the two major groups defined by the criteria described previously $(18-19)$. For the group of synovial fluids from patients suffering from inflammatory joint disease the sulphate concentrations found were significantly higher (t-test) than those found for the group of synovial fluids from patients suffering from chronic degenerative joint disease. There may be several reasons for the differences between the two groups. Due to the greater permeability of the blood-synovia-barrier in the case of inflammatory joint diseases, the higher sulphate concentration cannot be described as analogous to the higher protein concentrations found in these cases, because the concentrations of most constituents in synovial fluid approach the concentrations in serum with increasing permeability of the blood-synovia-barrier (19). An association of the differences in the concentrations of sulphate in the synovial fluid with the inflammatory activity of the joint process seems more likely. In inflammatory joint disease the metabolic activity in the synovial system and the degradation of the joint cartilage with degradation of sulphated proteoglycans and glycosaminoglycans are accelerated. Besides these processes there is an induction of biosynthetic activity for the reconstruction of the components of the synovial system mediated by cytokines and growth factors (20). Activation of regulatory processes enhancing the synthesis of new sulphated proteoglycans may therefore also be responsible for the higher concentration of sulphate in the synovial fluid in cases of inflammatory joint disease.

In four volunteers we studied the changes of concentration of sulphate in serum due to an intake of acetaminophen. An exponential time-dependent decrease of the concentration of sulphate in serum accompanying the elimination of acetaminophen was observed. The decay constant as well as the cumulative concentration decrease of sulphate in serum were not correlated with the dose of acetaminophen normalized for body weight, or with the peak acetaminophen concentration in serum. The role of sulphate in cellular metabolism as well as the sulphate depletion in serum due to drug metabolism have been described by other authors $(21-24)$. This sulphate trapping may be an intrinsic effect of antiinflammatory drugs (22-23). Chronic intake of drugs subject to conjugation with sulphate may lead to a permanently reduced sulphate concentration in serum. Sulphate trapping by drugs in serum may consecutively lead to a reduced sulphate concentration in the synovial fluid. Sulphate is necessary for the biosynthesis of sulphated proteoglycans, so that sulphate depletion in the synovial fluid may have a negative impact on the quantity and the composition of the proteoglycans synthesized $(2-4)$. These altered proteoglycans may enhance the destruction of the cartilage. Since several drugs used commonly in pain therapy of arthritis have sulphate-depleting effects like acetaminophen (24), this sulphate trapping may manifest itself as an adverse side-effect. The potential of such drugs for enhancing the progression of the cartilage destruction has to be studied further in clinical trials.

The determination of sulphate in serum may also be useful for the follow-up of patients suffering from intoxication with acetaminophen. Since the pool of sulphate is limited and may only be restored by metabolism of sulphur-containing amino acids, the course of the concentration of sulphate in serum gives additional important information in these circumstances. In animal experiments, a permanently low sulphate concentration in serum has been shown to result in non-linear kinetics and decreased efficiency for the elimination of drugs (25). 


\section{References}

1. De Meio RH. In: Greenberg DM, editors. metabolic pathways. 3rd ed. New York: Academic Press 1975; 7:287.

2. Van der Kraan PM, de Vries BJ, Vitters EL, van den Berg WB, van de Putte LBA. Inhibition of glycosaminoglycan synthesis in anatomically intact rat patellar cartilage by paracetamol-induced serum sulphate depletion. Biochem Pharmacol 1988; $37: 3683-90$.

3. Van der Kraan PM, de Vries BJ, van den Berg WB, Vitters E, van de Putte LBA. Effects of drug-mediated serum-sulphate depletion on glycosaminoglycan synthesis. Agents Actions $1988 ; 23: 55-7$.

4. Van der Kraan PM, de Vries BJ, Vitters EL, van den Berg WB, van de Putte LBA. The effect of chronic paracetamol administration to rat on the glycosaminoglycan content of patellar cartilage. Agents Actions 1990; 29:218-23.

5. Cole DEC, Landry DA. Determination of inorganic sulphate in human saliva and sweat by controlled - flow anion chromatography. Normal values in adult humans. J Chromatogr 1985; 337:267-78.

6. Hoffman DA, Wallace SM, Verbeek RK. Simple method for the determination of inorganic sulphate in human serum and urine using single - column ion chromatography. J Chromatogr 1991; 565:447-52.

7. Long GL, Winefolder JD. Limit of detection - a closer look at the IUPAC definition. Anal Chem 1983; 55/7:712A-24A.

8. Hammer R, Bozler G, Heinzel G, Koss FW. Modellentwicklung in der Pharmakokinetik, V. Teil. Arzneim-Forsch/ Drug Res 1977; 27(I):928.

9. Didgson KS, Spencer B. Studies on sulphates. 5. Determination of inorganic sulphate in the study of sulphates. Biochem J 1953; 55:436.

10. Lloyd AG. Studies on sulphatases. The use of barium chloranilate in the determination of enzymatically liberated sulphate. Biochem J 1959; 72:133-5.

11. Waheed A, van Etten RL. A spectrophotometric determination of sulphate ion and its application in studies of substrate purity and of aryl sulfatase a kinetics. Anal Biochem 1978; 89:550-66.

12. Lundquist P, Martensson J, Sörbö B, Öhmann S. Turbidimetry of inorganic sulphate, ester sulphate, and total sulfur in urine. Clin Chem 1980; 26:1180-1.

13. Small H, Stevens TS, Bauman WL. Novel ion exchange chromatographic method using conductimetric detection. Anal Chem 1975; 47:1801-9.

14. De Jong $P$, Burggraaf $M$. An ion-chromatographic method for the simultaneous determination of inorganic phosphate, bromide, nitrate, and sulphate in human serum. Clin Chim Acta $1983 ; 132: 63-71$.
15. Hyo JK, Rozman P, Madhu C, Klaasen CD. Homeostasis of sulphate an 3'-phosphoadenosine 5'-phosphosulfat in rats after acetaminophen administration. J Pharmacol Exp Ther 1992; 261:1015-21.

16. Reiter C, Müller S, Müller T. Improved method for the determination of sulphate in human serum using ion chromatography. J Chromatogr 1987; 413:251-6.

17. Meier MS, Schmidt-Kessen W. Untersuchungen über den Stoffwechsel des anorganischen Sulphates. Münch Med Wochenschr 1978; 120:357-62.

18. Greiling H, Kleesiek K. Die Synoviaanalyse und ihre differentialdiagnostische Bedeutung bei chronischen Gelenkerkrankungen. Intern Welt 1978; 4:121-30.

19. Kleesiek K. Untersuchungen zur Pathobiochemie des synovialen Systems und ihre Bedeutung für die Diagnostik und Therapie rheumatischer Erkrankungen [Habilitationsschrift]. Aachen, Germany, Medizinische Fakultät der RWTH Aachen, 1981.

20. Haubeck HD, Kock R, Fischer DC, van de Leur E, Hoffmeister $\mathrm{K}$, Schieth $\mathrm{B}$, et al. Transforming growth factor- $\beta 1$ is a major stimulator of hyaluronan synthesis in human synovial lining cells. Arthr Rheum 1995; 38/5:669-77.

21. Greiling H. Sulfat als limitierender Faktor des Zellstoffwechsels. Angew Chem 1961; 43:73.

22. Greiling H, Schuler B. Zur Wirkungsweise der Salizylsäure, Azetylsalizylsäure und des Salizylamids. Z Rheumaforsch $1963 ; 22: 47-56$.

23. Levy G, Galinsky RE, Lin JH. Pharmacokinetic consequences and toxicologic implications of endogenous depletion. Drug Metabol Rev 1982; 13:1009-20.

24. Morris ME, Levy G. Serum concentration and renal excretion by normal adults of inorganic sulphate after acetaminophen, ascorbic acid, or sodium sulfate. Clin Pharmacol Ther 1983; 33:529-36.

25. Galinsky RE, Levy G. Dose- and time-dependent elimination of acetaminophen in rats. J Pharmacol Exp Ther 1981; 219:14-20.

Received February 21/June 9, 1997

Corresponding author: Dipl.-Chem. Dr. med. Rüdiger Kock, Institut für Klinische Chemie und Pathobiochemie, Universitätsklinikum der RWTH Aachen, Pauwelsstrasse 30, D-52057 Aachen, Germany

Tel.: +49-241-80-88681, Fax: +49-241-8888-512 
